\title{
Tuning of interfacial interactions in poly(isoprene) ferroelastomer by surface modification of embedded metallic iron nanoparticles
}

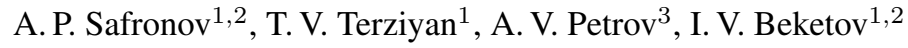 \\ ${ }^{1}$ Ural Federal University, Institute of Natural Sciences and Mathematics, \\ Yekaterinburg, 19 Mira Str., 620002, Russia \\ ${ }^{2}$ Institute of Electrophysics UB RAS, Yekaterinburg, 106 Amundsen Str.,620016, Russia \\ ${ }^{3}$ Uralplast LLC, Yekaterinburg, 7 Schorsa Str., 620142, Russia \\ alexander.safronov@urfu.ru, tatiana.terzian@urfu.ru,beketov@iep.uran.ru,avp@labural.com
}

DOI 10.17586/2220-8054-2021-12-4-520-527

\begin{abstract}
Zero-valent metallic iron nanoparticles (NPs) with modified surface were embedded in poly(isoprene) (PI) and the enthalpy of interfacial adhesion in resulted ferroelastomers was evaluated. Iron NPs were synthesized by the method of electrical explosion of wire (EEW) in inert gas. Modification of their surface was performed by the in situ liquid treatment of the active condensed NPs in the EEW installation. The enthalpy of mixing of poly(isoprene) with Fe NPs was determined using thermochemical cycle based on the isothermal calorimetry measurement of the enthalpy of dissolution of PI/Fe composites in chloroform at $25^{\circ} \mathrm{C}$. Using these values the enthalpy of adhesion of PI to the surface of modified Fe NPs was evaluated using Langmuir-type isotherm. It was shown that the enthalpy of adhesion strongly depends on the properties of the surface of Fe NPs and its modification. It was the lowest in the case of oxidized Fe NPs and the highest for Fe NPs which surface was modified by pre-deposited polymeric shells.
\end{abstract}

Keywords: nanocomposites, zero-valent iron nanoparticles, ferroelastomers, surface modification, enthalpy of adhesion

Received: 25 June 2021

Revised: 23 July 2021

\section{Introduction}

Zero valent iron nanoparticles have received considerable interest because of their potential applications in many diverse fields, including ferrofluids, biomedical materials, sensors, catalysts, magnetic and electro-conductive materials [1-5]. In many cases nanoparticles are incorporated into polymeric composites [2-5]. In particular, it is the case of magnetically active polymeric composites - ferroelastomers, which combine the elasticity of a polymer with the magnetic properties of embedded solid magnetic particles [5]. These materials provide the advantage of remote control of their mechanical characteristics by the application of the external magnetic field. The integral performance of ferroelastomers depends on the combination of their mechanical and magnetic responses. Meanwhile, these two aspects are in some respect controversial. The increase in the load of solid magnetic particles improves the magnetic properties of a ferroelastomer, but at the same, time it can decrease its mechanical strength. The weak point for the ultimate tensile stress in a composite is the polymer/solid interface. Hence, enhancement of the adhesion at the polymer/solid interface can be a solution to the problem. The major route to provide this is the modification of embedded solid magnetic particles.

There are two main ways to modify the surface of inorganic particles [6]. The first is accomplished through surface absorption of small molecules or polymers, the second method is based on covalent bonding of a modifier to the groups existing at the surface of the particles. Typically, surface adsorption is related to various surfactants like oleic acid and its salts [7-9]. Covalent bonding, as well as surface graft-polymerization, requires the presence of chemically active groups at the solid surface, like hydroxyls [10-13]. The surface of zero-valent metal nanoparticles, however, is lacking active functional groups, and in this case, the modification by covalent bonding becomes a complex multi-step procedure $[14,15]$.

A combination of the adsorption and bonding mechanisms of modification of zero-valent metal nanoparticles was reported in references [16,17]. Modification was a one step process performed in situ during the synthesis of $3 \mathrm{~d}$ metal nanoparticles by the method of the electrical explosion of wire (EEW). This is a highly productive method based on the evaporation of the metal wire by the high voltage electrical discharge with consequent condensation of spherical particles in inert gas [18,19]. As-synthesized particles were immersed in a liquid solution of a modifier, which was deposited at the interface by chemical bonding, initiated by the active surface of metal particles.

The effect of the modification of the surface of solid particles on their adhesion to a polymer can be evaluated by the thermodynamic approach, which gives the enthalpy of formation of nanocomposite as a measure for the enthalpy 
of adhesion at solid/polymer interface. This approach was successfully elaborated in our earlier studies concerning composites based on various polymers filled with metal and metal oxide nanoparticles [20-22].

The objective of the present work was to study the influence of the surface modification of metallic iron nanoparticles on the enthalpy of their interaction with poly(isoprene) in ferroelastomer. This polymeric matrix may be considered on one hand as a good model for the interaction of the amorphous polymer in an equilibrium conformational state with the surface of metal nanoparticles. On the other hand, poly(isoprene) is the commercially available polymer widely used in rubber industry in general and for the production of ferroelastomers in particular.

\section{Experimental part}

\subsection{Synthesis and surface modification of Fe MNPs}

The method of the electrical explosion of wire (EEW) was used for the synthesis of metallic iron magnetic nanoparticles (Fe NPs). The detailed description of EEW equipment designed at Institute of Electrophysics of RAS (Yekaterinburg, RF) is given elsewhere [18,19]. The method is based on the evaporation of a portion of a metal wire by the electrical high voltage discharge in the explosion chamber filled with an inert gas. Further condensation of the expanding metal vapors resulted in the formation of spherical NPs. The applied voltage was $30 \mathrm{KV}$ and the length of the exploded portion of wire was $90 \mathrm{~mm}$. The wire was continuously fed to the explosion chamber. The high voltage source was concurrently recharged after each explosion, and the process was repeated in the pulsed manner. It resulted in the rapid production of NPs $(200 \mathrm{~g} / \mathrm{h})$. The reaction chamber was filled with a circulating 70:30 mixture of Ar and $\mathrm{N}_{2}$ which provided the working gas pressure of $0.12 \mathrm{MPa}$.

The in-situ liquid-phase modification of MNPs was made by the immersing of the as-prepared Fe NPs in hexane, toluene, $0.6 \%$ solution of oleic acid in hexane, and $1 \%$ solutions of poly(isoprene) (PI) and poly(styrene) (PS) in toluene in the special hopper attached to the EEW installation and filled with the inert gas mixture. The details of the modification are given elsewhere $[16,17]$. All the modifiers were obtained from commercial suppliers and used without further purification.

As it was shown earlier [16], hexane is an inert liquid for the active surface of the as-prepared Fe NPs, and if kept under hexane, the metallic surface of Fe MNPs remained intact. It makes such samples highly pyrophoric. In order to make them stable in the air controlled oxidation should be performed to provide the oxide shell $1.5-3 \mathrm{~nm}$ in thickness on the surface of Fe MNPs [23]. Toluene is not inert to the as-prepared Fe NPs. Aromatic hydrocarbons condense on the surface of $3 \mathrm{~d}$ metal NPs producing the layer of polycyclic aromatic hydrocarbons. The details of the deposition and its mechanism are given elsewhere [16]. The treatment of Fe NPs by the solutions of oleic acid, poly(isoprene), poly(styrene) provided the deposition of these modifiers on the surface. The deposited layer was 3-5 nm (TEM) in thickness and protected NPs from further oxidation.

The batches of modified Fe NPs taken for the study and their selected parameters are given in Table 1. Subsequently the batches will be addressed according to the marks listed in this table.

TEM images of the obtained Fe NPs are presented in Fig. 1. The particles are spherical and non-agglomerated. Particle size distribution obtained by the image analysis is lognormal with a median value of $59 \mathrm{~nm}$ and a logarithmic dispersion of 0.478. Fig. 1B presents the image of the protective oxide layer on the surface of NPs from batch $\mathrm{Fe}_{O x}$.

The specific surface area of the NPs was determined by the low temperature adsorption of nitrogen using Micromeritics TriStar 3000 analyzer. Phase composition of NPs was characterized by XRD (Bruker D8 DISCOVER). TEM and HTEM were performed using a JEOL JEM2100 microscope operating at $200 \mathrm{kV}$.

\subsection{Preparation of poly(isoprene) ferroelastomers}

Poly(isoprene) was the commercial product (RF - GOST 14925-79 corr. 1-8). The weight average molecular weight of PI MW= $5.4 \times 10^{5}$ was measured by viscometry in benzene solution at $25{ }^{\circ} \mathrm{C}\left(K_{\eta}=5.02 \times 10^{-4} \mathrm{dm}^{3} / \mathrm{g}\right.$, $a=0.675)$.

Nanocomposites based on PI with embedded Fe NPs were prepared by casting onto the glass substrate. First, the $5 \%$ stock solution of PI in toluene was prepared and equilibrated. Then, the weighted amounts of Fe NPs were dispersed in $15 \mathrm{~mL}$ of stock solution to prepare mixed suspensions. They were homogenized in the Cole Parmer ultrasound processor at $20 \mathrm{KHz}$ and $300 \mathrm{~W}$ for $10 \mathrm{~min}$ in a pulse/pause regime (pulse $-15 \mathrm{sec}$, pause $-10 \mathrm{sec}$ ). In all the cases except pyrophoric $\mathrm{Fe}_{0}$ air-dry powders of NPs were taken. $\mathrm{Fe}_{0}$ was used in the form of the hexane suspension. The load of modified Fe NPs in the suspension varied to provide 10, 20, 30, 40, 50, 60, 70, 80, $90 \%$ of the filler in finally obtained ferroelasts. Homogenized suspensions of intact and modified Fe NPs in toluene solution of PI were cast onto the Petri dishes and dried to the constant weight in vacuo at $25^{\circ} \mathrm{C}$. 
TABLE 1. Batches of modified Fe NPs and their selected parameters: specific surface area $\mathrm{S}_{B E T}$, content of carbon and crystalline phase composition

\begin{tabular}{|c|c|c|c|c|c|}
\hline No & Batch & Preparation & $\begin{array}{l}\mathrm{S}_{B E T} \\
\left(\mathrm{~m}^{2} / \mathrm{g}\right)\end{array}$ & $\begin{array}{c}\text { Carbon } \\
\text { content }(\%)\end{array}$ & $\begin{array}{l}\text { Crystalline } \\
\text { phases }(\%)\end{array}$ \\
\hline 1 & $\mathrm{Fe}_{0}$ & $\begin{array}{c}\text { Intact Fe NPs kept } \\
\text { under hexane }\end{array}$ & 8.4 & 0.08 & $\begin{array}{l}\alpha \mathrm{Fe}: 97.7 \\
\gamma \mathrm{Fe}: 2.3\end{array}$ \\
\hline 2 & $\mathrm{Fe}_{O x}$ & Controlled oxidation & 8.5 & 0.08 & $\begin{array}{c}\alpha \mathrm{Fe}: 95.0 \\
\gamma \mathrm{Fe}: 1.9 \\
\mathrm{Fe}_{2} \mathrm{O}_{3}: 3.1\end{array}$ \\
\hline 3 & $\mathrm{Fe}_{T}$ & Modification by liquid toluene & 7.8 & 0.25 & $\begin{array}{c}\alpha \mathrm{Fe}: 88.6 \\
\gamma \mathrm{Fe}: 6.7 \\
\mathrm{Fe}_{2} \mathrm{O}_{3}: 4.7\end{array}$ \\
\hline 4 & $\mathrm{Fe}_{O A}$ & $\begin{array}{c}\text { Modification by } 0.6 \% \text { solution } \\
\text { of oleic acid in hexane }\end{array}$ & 8.4 & 0.39 & $\begin{array}{l}\alpha \mathrm{Fe}: 97.5 \\
\gamma \mathrm{Fe}: 62.5\end{array}$ \\
\hline 5 & $\mathrm{Fe}_{P I}$ & $\begin{array}{l}\text { Modification by } 1 \% \text { solution } \\
\text { of poly(isoprene) in toluene }\end{array}$ & 7.8 & 0.56 & $\begin{array}{c}\alpha \mathrm{Fe}: 89.5 \\
\gamma \mathrm{Fe}: 6.3 \\
\mathrm{Fe}_{2} \mathrm{O}_{3}: 4.2\end{array}$ \\
\hline 6 & $\mathrm{Fe}_{P S}$ & $\begin{array}{c}\text { Modification by } 1 \% \text { solution } \\
\text { of poly(styrene) in toluene }\end{array}$ & 7.8 & 0.45 & $\begin{array}{c}\alpha \mathrm{Fe}: 89.8 \\
\gamma \mathrm{Fe}: 6.5 \\
\mathrm{Fe}_{2} \mathrm{O}_{3}: 3.7\end{array}$ \\
\hline
\end{tabular}

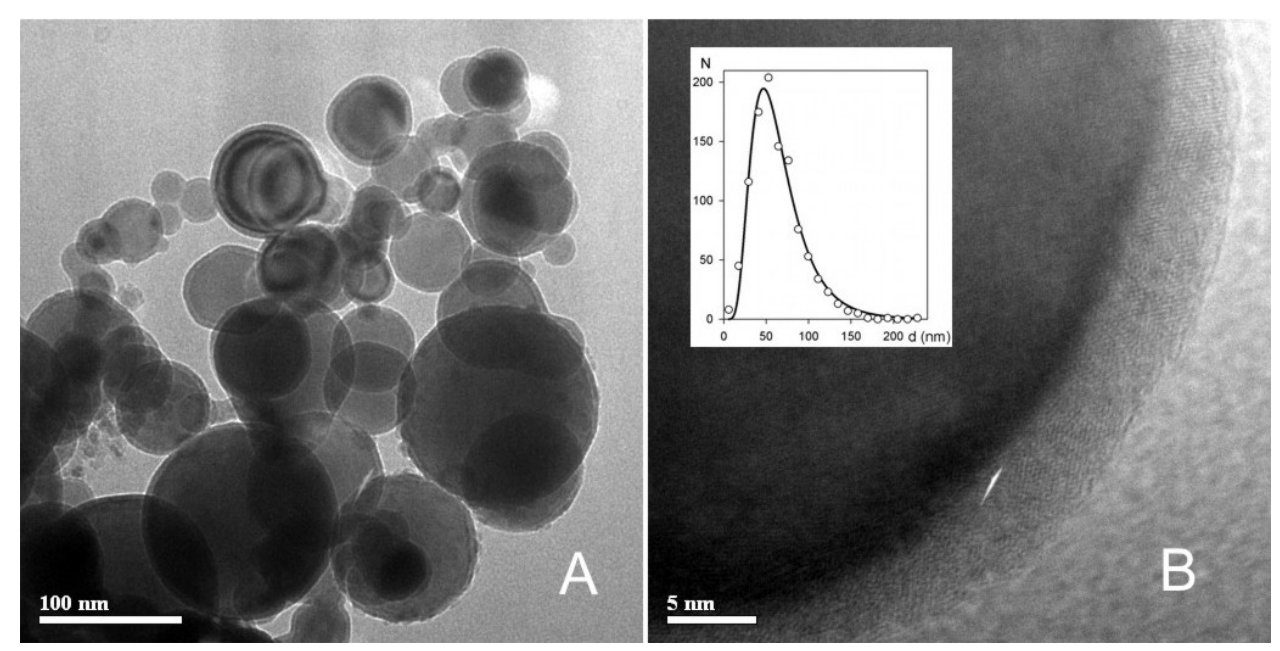

FIG. 1. (A) - TEM image of Fe NPs produced by EEW and taken as a filler for the composite. (B) - HTEM image of $\mathrm{Fe}_{O x} \mathrm{NP}$ with the protective oxide layer on the surface. Inset - particle size distribution (1043 particles) 


\subsection{Calorimetric measurements}

The enthalpies of the processes incorporated in the thermochemical cycle were measured in isothermal conditions at $25^{\circ} \mathrm{C}$ using Calvet 3D calorimeter SETARAM C80. Ampoule mixing cells were elaborated. The weighted amounts (ca 20 - $90 \mathrm{mg}$ ) of Fe NPs, or PI, or composite with certain Fe NPs content were placed into a thin glass ampoule (ca $0.5 \mathrm{~cm}^{3}$ ) and dried to a constant weight. Then the ampoules were sealed, placed in a special holder, which was mounted in the stainless steel cell $\left(10 \mathrm{~cm}^{3}\right)$, and loaded with $5 \mathrm{~mL}$ of chloroform. Two assembled cells were located in the ports of the calorimeter set at $25{ }^{\circ} \mathrm{C}$. Thermal equilibration took ca. $2-3 \mathrm{hrs}$ and was monitored by the baseline. When the baseline drift fell below $0.01 \mathrm{~mW}$ within $30 \mathrm{~min}$, the calorimetric experiment in one of the cells was started by breaking the ampoule in chloroform. The other cell was the reference. The heat evolution was observed for ca 60 min until the equilibrium baseline was reestablished. Then, the experiment in the second cell was performed in a similar way. Typically measured heat effects fell within $0.1-5 \mathrm{~J}$ range, depending on the load in the ampoule. The relative error of measurements of the heats of dissolution and the heats of wetting was estimated in $5 \%$ for the heat effects ranging from 0.1 to $0.5 \mathrm{~J}$ and $2 \%$ for the heat effects in the $0.5-5 \mathrm{~J}$ range.

\section{Results and discussion}

The enthalpy of formation of filled polymer composite, which depends on the interaction at the solid/polymer interface cannot be measured in the direct calorimetric experiment, as the solid particles do not spontaneously mix with polymer matrix. In such cases, the enthalpy can be determined by the proper combination of the steps, which can be performed in the calorimeter. These steps for the evaluation of the enthalpy of formation of the polymeric nanocomposite with embedded solid particles are presented schematically in Fig. 2 [20].

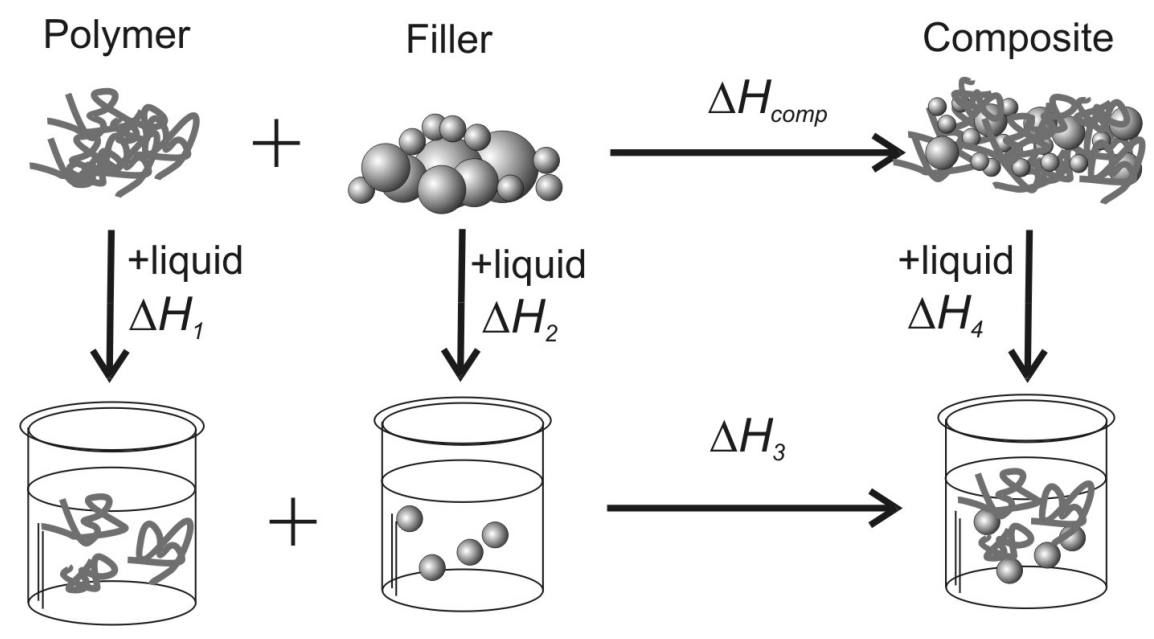

FIG. 2. Thermochemical cycle for the determination of the enthalpy of formation of a polymer composite

The target thermodynamic function in the thermochemical cycle (Hess cycle) in Fig. 2 is $\Delta H_{\text {comp }}-$ the enthalpy of formation of composite from its constituents. However, the mixing of a composite cannot be performed in the calorimetric cell; the composite with the definite filler content should be prepared separately. In order to evaluate $\Delta H_{c o m p}$, one should go through consequent steps of the cycle in Fig. 2, which is based on the interaction of the components and the composite with an appropriate liquid. This liquid should be a good solvent for the polymer and should provide full dissolution of the polymer and the composite. In the present study, we used chloroform for such a liquid, as it is a good solvent for poly(isoprene) and for all its composites.

In the first step of the cycle, the enthalpy of dissolution $\left(\Delta H_{1}\right)$ of a polymer in a large extent of liquid was measured. At the same step, but in a separate experiment, the powdered filler was wetted by the same liquid with the enthalpy effect $\Delta H_{2}$. In the second step of the cycle the polymer solution was mixed with the suspension of the filler with the heat effect $\Delta H_{3}$. In the final step of the cycle, the solvent should be eliminated to give the composite with the definite filler content. Obviously, it was the reversal of the dissolution of the composite in the large extent of the liquid with the enthalpy effect $\Delta H_{4}$. Finally, the enthalpy of formation of the composite was calculated as the linear combination of enthalpy effects for these steps:

$$
\Delta H_{\text {comp }}=\omega_{1} \Delta H_{1}+\omega_{2} \Delta H_{2}+\Delta H_{3}-\Delta H_{4},
$$


TABLE 2. The enthalpy of dissolution in chloroform at $25{ }^{\circ} \mathrm{C}$ for poly(isoprene) ferroelastomers with embedded Fe NPs with intact and modified surface

\begin{tabular}{|c|c|c|c|c|c|c|c|c|c|c|}
\hline & \multicolumn{10}{|c|}{ Enthalpy of dissolution of a composite, $\Delta H_{4}(\mathrm{~J} / \mathrm{g})$} \\
\hline$\omega_{2}$ & 0.1 & 0.2 & 0.3 & 0.4 & 0.5 & 0.6 & 0.7 & 0.8 & 0.9 & $1.0 *$ \\
\hline $\mathrm{Fe}_{0}$ & -7.63 & -6.75 & -5.91 & -5.05 & -4.18 & -3.34 & -2.52 & -1.79 & -1.32 & -4.86 \\
\hline $\mathrm{Fe}_{O x}$ & -7.38 & -6.40 & -5.40 & -4.47 & -3.42 & -2.73 & -1.95 & -1.34 & -0.94 & -1.05 \\
\hline $\mathrm{Fe}_{T}$ & -7.21 & -6.03 & -4.88 & -3.62 & -2.24 & -1.05 & -0.15 & 0.47 & 0.60 & -4.27 \\
\hline $\mathrm{Fe}_{O A}$ & -7.20 & -6.06 & -5.08 & -4.27 & -3.44 & -2.70 & -1.96 & -1.34 & -0.95 & -1.47 \\
\hline $\mathrm{Fe}_{P I}$ & -7.44 & -6.58 & -5.76 & -4.92 & -4.05 & -3.19 & -2.42 & -1.76 & -2.18 & -21.07 \\
\hline $\mathrm{Fe}_{P S}$ & -7.64 & -6.88 & -6.13 & -5.36 & -4.58 & -3.75 & -2.96 & -2.45 & -2.92 & -21.29 \\
\hline
\end{tabular}

${ }^{*}$ The value of $\Delta H_{4}$ at $\omega_{2}=1$ is the enthalpy of wetting of a filler $\Delta H_{2}$

${ }^{* *}$ The value of the enthalpy of dissolution on poly(isoprene), $\Delta H_{1}$, was equal to $-8.39 \mathrm{~J} / \mathrm{g}$. This was the same in all cases.

where $\omega_{1}, \omega_{2}$ are the weight fractions of the polymer (PI) and the filler (Fe MNPs) in the composite, which normalize $\Delta H_{c o m p}$ value per $1 \mathrm{~g}$ of the composite. The resulted value of $\Delta H_{\text {comp }}$ obtained in the thermochemical cycle corresponds to the temperature, at which the calorimetric measurements were made; and it was $25^{\circ} \mathrm{C}$ in the present study.

Table 2 gives the values of the enthalpy of dissolution of poly(isoprene) in chloroform $\left(\Delta H_{1}\right)$, the enthalpy of wetting of Fe NPs with chloroform $\left(\Delta H_{2}\right)$, and the enthalpy of dissolution of composites $\left(\Delta H_{4}\right)$ with different Fe NPs content $\left(\omega_{2}\right)$. They were measured in calorimeter in the entire composition range for the composites filled with zerovalent metallic iron NPs with the intact and modified surface. $\Delta H_{3}$ values in all the cases fell within the experimental error and are not listed.

The values given in Table 2 were used for calculating the enthalpy of formation of nanocomposites with embedded Fe NPs according to equation (1). They are plotted against the weight fraction of Fe NPs in Fig. 3. The values of the enthalpy of formation $\left(\Delta H_{c o m p}\right)$ are negative for all the nanocomposites; it means that the interaction between PI matrix and Fe NPs is energetically favorable. In all the cases, the concentration dependence is the smooth curve with minimum. It is clear that the modification of Fe NPs strongly affects $\Delta H_{\text {comp }}$ values. The largest absolute values were obtained for the ferroelastomers with $\mathrm{Fe}_{P I}$ and $\mathrm{Fe}_{P C}$ NPs, which were modified by the polymeric layer at the surface. The lowest absolute values of $\Delta H_{\text {comp }}$ correspond to $\mathrm{Fe}_{O x}$ NPs with the passivating oxide layer on the surface. Qualitatively, these results indicate that the modification of the surface of Fe NPs improves interaction with PI matrix as a rule. The quantitative consideration needs more detailed treatment of the concentration plots for $\Delta H_{\text {comp }}$.

The enthalpy of interaction at the interface is the result of the numerous elementary molecular contacts among the base-units of a polymer and the solid surface. If these contacts are short-range and independent (no cooperative forces are involved), then the total enthalpy of interaction will be proportional to the number of elementary contacts established at the interface. The number of such contacts is proportional to the fraction of the surface occupied by the base-units of a polymer. If the entire surface of the solid particle is filled with base-units of a polymer, then the enthalpy of interfacial interaction comes to saturation. Such a consideration leads to a Langmuir-type [24] equation for the enthalpy of adhesion at the polymer/solid interface:

$$
\Delta H_{a d h}=\Delta H_{a d h}^{\infty} \frac{K C_{P}}{1+K C_{P}} .
$$

Here, $\Delta H_{a d h}$ is the enthalpy of all contacts established by monomeric units with the surface of NPs at certain concentration of polymer, $\Delta H_{a d h}^{\infty}$ is the enthalpy of all the contacts in the saturated layer, $K$ is the effective constant of the formation of an adhesive contact, $C_{P}$ is the concentration of a polymer (PI) in g per $1 \mathrm{~m}^{2}$ of the solid surface.

The function $\left(\Delta H_{a d h}\right)$ and the variable $\left(C_{P}\right)$ are related to the enthalpy of formation of composite and to the weight fraction of the filler by the obvious equations:

$$
\begin{gathered}
\Delta H_{a d h}=\frac{\Delta H_{c o m p}}{\omega_{2} S_{B E T}}, \\
C_{P}=\frac{1-\omega_{2}}{\omega_{2} S_{B E T}} .
\end{gathered}
$$




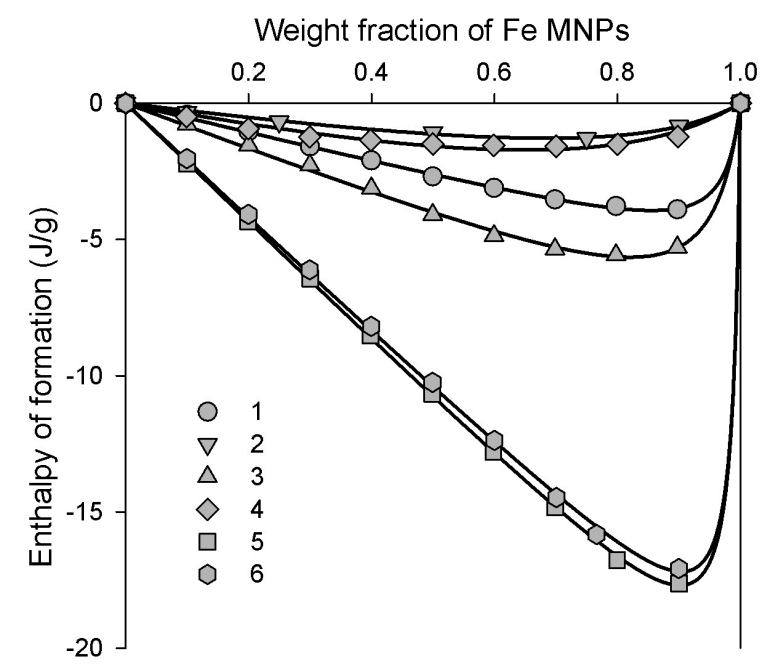

FIG. 3. Dependence of the enthalpy of formation of poly(isoprene) ferroelastomers on the content of Fe NPs with the intact and modified surface for systems filled with $1-\mathrm{Fe}_{0}, 2-\mathrm{Fe}_{O x}, 3-\mathrm{Fe}_{T}$, $4-\mathrm{Fe}_{O A}, 5-\mathrm{Fe}_{P I}, 6-\mathrm{Fe}_{P S}$. The solid curves are the result of the interpolation by equation (5)

TABLE 3. Parameters of adhesion: $\Delta H_{a d h}^{\infty}$ and $K$ for the interaction of poly(isoprene) with the surface of the intact and modified Fe MNPs in poly(isoprene) ferroelastomers

\begin{tabular}{|c|c|c|c|c|c|c|}
\hline Batch & $\mathrm{Fe}_{0}$ & $\mathrm{Fe}_{O x}$ & $\mathrm{Fe}_{T}$ & $\mathrm{Fe}_{O A}$ & $\mathrm{Fe}_{P I}$ & $\mathrm{Fe}_{P S}$ \\
\hline$\Delta H_{a d h}^{\infty}\left(\mathrm{J} / \mathrm{m}^{2}\right)$ & -0.64 & -0.32 & -1.08 & -0.48 & -2.79 & -2.69 \\
\hline$K\left(\mathrm{~m}^{2} / \mathrm{g}\right)$ & 299.0 & 41.6 & 164.0 & 29.0 & 655.0 & 697.0 \\
\hline
\end{tabular}

Substitution of equations (3), (4) in equation (2) gives the relation of the experimentally determined value of $\Delta H_{c o m p}$ to the parameters of equation (2) $-\Delta H_{a d h}$ and $K$ :

$$
\Delta H_{c o m p}=\Delta H_{a d h}^{\infty} \frac{K\left(1-\omega_{2}\right) \omega_{2} S_{B E T}}{K\left(1-\omega_{2}\right)+\omega_{2} S_{B E T}} .
$$

Figure 4 presents the model concentration dependencies of $\Delta H_{c o m p}$ calculated for different parameter sets. One can see that the curves have the same shape as the experimental plots presented in Fig. 3. In general, $\Delta H_{a d h}^{\infty}$ governs the scale of the enthalpy changes, while $K$ determines the position of the minimum on the curves. Large values of $K$ correspond to the strong adhesion at the interface and it shifts the minimum of $\Delta H_{\text {comp }}$ to the large weight fraction of NPs in the composition (compare curves 1 and 2 in Fig. 4). This occurs because the adhesion layers become saturated at the relatively low levels of polymer content. If the adhesion is weak (i.e., low $K$ ), a large amount of the polymer is required to saturate the adhesion layers and the minimum of $\Delta H_{c o m p}$ is shifted to low fraction of NPs in the composition. If $\Delta H_{a d h}^{\infty}$ is constant, the increase of $K$ not only shifts the curve to the higher content of NPs but makes the minimum deeper. It is the result of the normalization of $\Delta H_{c o m p}$ value to $1 \mathrm{~g}$ of the composition. At high $K$ the enthalpy of interaction corresponds to the relatively small amount of the polymer and it enlarges the negative values of $\Delta H_{\text {comp }}$.

At a constant $K$, the negative values of $\Delta H_{\text {comp }}$ linearly increase with $\Delta H_{a d h}^{\infty}$ as each adhesion contact with surface becomes stronger (compare curves 2 and 3 in Fig. 4).

Experimental values of $\Delta H_{\text {comp }}$ in Fig. 3 were fitted by equation (5) to get adhesion parameters $\Delta H_{a d h}^{\infty}$ and $K$ for PI ferroelastomers under study. Lines in Fig. 3 correspond to this interpolation. It is clearly seen that simple Langmuir model fits well the experimental results for the enthalpy of formation of nanocomposites.

Table 3 gives the parameters $\Delta H_{a d h}^{\infty}$ and $K$ obtained by fitting the concentration plots of $\Delta H_{\text {comp }}$ (Fig. 3) by equation (5).

The weakest is the adhesion of PI to the surface of $\mathrm{Fe}_{O x}$ NPs with the passivating oxide layer. The absolute $\Delta H_{a d h}^{\infty}$ value is twice lower than the value for the non-passivated $\mathrm{Fe}_{0}$ with intact metal surface. This means that the passivation of metallic Fe NPs by its oxidation is unfavorable for the adhesion of PI. On the contrary, adhesion of PI to FeT NPs is almost twice stronger than that to the intact metallic surface. In reference [16], it was shown that the treatment of the intact surface of $3 \mathrm{~d}$ metal by the aromatic liquids resulted in the formation of polycyclic aromatic 


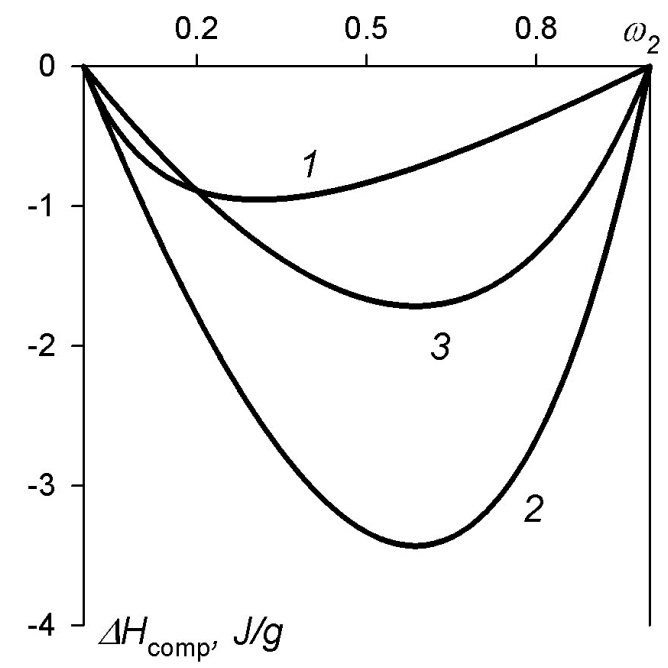

FIG. 4. The model concentration dependencies of $\Delta H_{\text {comp }}$ calculated for: (1) $K=2 \mathrm{~m}^{2} / \mathrm{g}$, $\Delta H_{a d h}^{\infty}=-1 \mathrm{~J} / \mathrm{m}^{2}$; (2) $K=20 \mathrm{~m}^{2} / \mathrm{g}, \Delta H_{a d h}^{\infty}=-1 \mathrm{~J} / \mathrm{m}^{2}$; (3) $K=20 \mathrm{~m}^{2} / \mathrm{g}, \Delta H_{a d h}^{\infty}=-0.5 \mathrm{~J} / \mathrm{m}^{2}$

hydrocarbons (PAH) on the surface. According to the results presented in Fig. 3 and Table 3, the layer of PAH substantially improves the adhesion of PI to the metallic surface of Fe MNPs. PI is a non-polar polymer with p-bonds in its monomeric units. Molecular orbitals on the double bonds more likely will interact with the delocalized electrons, which are present in the metal and in the benzene rings of PAH, than with the ionic crystalline oxide structure.

The strongest adhesion was obtained for the composites with Fe NPs modified by polymeric layers. Both polymeric modifiers - PI and PS contain $\pi$-electron density in their monomeric units and can effectively interact with PI matrix. Furthermore, it is well-known [25] that the macromolecules in the polymeric shells on the surface contain numerous loops and free tails, which substantially enhance the possibilities of the adhesion of PI matrix by interfusion.

Unexpectedly, $\mathrm{Fe}_{O A}$ showed rather poor adhesion to the PI matrix. It was lower than that for the intact $\mathrm{Fe}_{0}$ but still stronger than for $\mathrm{Fe}_{O x}$. Oleic acid is commonly known as a good dispersant for the suspensions of metal and metal oxide particles in the non-polar liquids [1]. Its activity is based on the formation of the oriented adsorption layers on the surface of the particles. Usually, metal surfaces isare oxidized, and thus, the mechanism of oleic acid adsorption on the metal and on the metal oxide is likely the same. The polar heads of the oleic acid stick to the polar surface of the oxide, while hydrocarbon tails form the hydrophobic shell around the particle. However, this is not the case for the $\mathrm{Fe}_{O A}$ NPs studied in the present work. Modification by oleic acid was performed on the intact metal surface not exposed to the air, which might not favor the formation of the oriented layer. No such layer on the surface of Fe NPs was found by HTEM in our previous work [23]. Oleic layer on the surface was amorphous and the polar carboxyl residues of oleic acid were facing any direction. Therefore these polar groups might as well be exposed to PI matrix in the composite, and might effectively diminish the adhesion.

The trends in $K$ values (Table 3) generally follow the trends in $\Delta H_{a d h}^{\infty}$. This means that strong molecular contacts provide higher adherence at the interface. However, $K$ being the effective constant of the formation of adhesion contact relates to the free energy of the adhesion, which includes not only the enthalpy, but also the entropy contribution. Most likely it is the reason for the deviations from the linear correlation between $\Delta H_{a d h}^{\infty}$ and $K$ (e.g. in the case of $\mathrm{Fe}_{0}$, see Table 3).

\section{Conclusions}

The evaluation of the interaction energy at the interface between the polymeric matrix and dispersed solid particles is crucial for the development of the advanced composite polymeric materials. Specifically, it relates to the elastic composites with embedded magnetic nanoparticles - ferroelastomers. In the present study, we have used thermodynamic approach based on the thermochemical cycle to evaluate the enthalpy of formation of poly(isoprene) ferroelastomers with metal Fe NPs. We have taken Fe NPs with different surface treatment to study the influence of the surface modification on the enthalpy of interaction between poly(isoprene) matrix and the surface of embedded Fe NPs. In all the nanocomposites studied, the enthalpy of interaction between poly(isoprene) and Fe NPs was negative; it indicated adhesion between components at the polymer/solid interface. The dependence of the enthalpy of interaction on the NP's content in poly(isoprene) ferroelastomers is a smoothly shaped curve with a minimum. The simple Langmuir-type model was shown to be a good choice for the quantitative description of the experimental data 
and provided solid grounds for the consideration of the role of surface modification on poly(isoprene)/Fe interaction in the elastic nanocomposites.

The negative values of the enthalpy of adhesion increase almost ten-fold in a series $\mathrm{Fe}_{O x}$ (oxidized surface) $\mathrm{Fe}_{O A}$ (deposited oleic acid) - $\mathrm{Fe}_{0}$ (intact metal surface) - $\mathrm{Fe}_{T}$ (deposited polycyclic aromatics) - FePI (deposited poly (isoprene) $)=\mathrm{Fe}_{P S}($ deposited poly(styrene)). It supports the delocalization of $\pi$-electrons as the likely source for the interaction at the interface. Poly(isoprene) contains unsaturated double bond in each monomeric unit in the macromolecule. The intact Fe surface can participate in such delocalization due to the electronic gas in the metal lattice. The adhesion with poly(isoprene) matrix further improves when the intact Fe surface is covered by organic deposits with unsaturated electronic structures (double bonds, benzene rings). Meanwhile, if the metal surface is covered by oxide shell with ionic crystal lattice, the adhesion of poly(isoprene) diminishes. In a whole, the obtained results revealed that the in-situ surface modification of zero-valent iron nanoparticles in the EEW synthesis allowed controlled tuning of molecular adhesion at polymer/solid interface.

\section{Acknowledgement}

The research was supported by Russian Science Foundation grant 20-12-00031.

\section{References}

[1] Li L., Hu J., Shi X., Fan M., Luo J., Wei X. Nanoscale zero-valent metals: a review of synthesis, characterization, and applications to environmental remediation. Environ Sci Pollut Res, 2016, 23, P. 17880-17900.

[2] Yang T.-I., Brown R.N.C., Kempel L. C., Kofinas P. Magnetodielectric properties of polymer-Fe ${ }_{3} \mathrm{O}_{4}$ nanocomposites. J Magn Magn Mater, 2008, 320(31), P. 2714-2720.

[3] Jamal E.M.A., Joy P.A., Kurian P., Anantharaman M.R. Synthesis of nickel rubber nanocomposites and evaluation of their dielectric properties, Mater Sci Eng B-Adv, 2009, 156(13), P. 24-31.

[4] Kong I., Ahmad S. H., Abdullah M. H., Hui D., Yusoff A.N., Puryanti D. Magnetic and microwave absorbing properties of magnetite thermoplastic natural rubber nanocomposites. J Magn Magn Mater, 2010, 322(21), P. 3401-3409.

[5] Stepanov G.V., Chertovich A.V., Kramarenko E.Yu. Magnetorheological and deformation properties of magnetically controlled elastomers with hard magnetic filler. J Magn Magn Mater, 2012, 324(21), P. 3448-3451.

[6] Kango S., Kalia S., Celli A., Njuguna J., Habibi Y., Kumar R. Surface modification of inorganic nanoparticles for development of organicinorganic nanocomposites - a review. Progress Polym Sci, 2013, 38, P. 1232-1261.

[7] Yuan W., Yuan J., Zhou L., Wu S., Hong X. Fe ${ }_{3} \mathrm{O}_{4}$ @ poly(2-hydroxyethyl methacrylate)-graft-poly(3-caprolactone) magnetic nanoparticles with branched brush polymeric shell. Polymer, 2010, 51, P. 2540-2547.

[8] Pich A., Bhattacharya S., Ghosh A., Adler H.-J.P. Composite magnetic particles: 2. Encapsulation of iron oxide by surfactant-free emulsion polymerization. Polymer, 2005, 46, P. 4596-4603.

[9] Campanella A., Di Z., Luchini A., Paduano L., Klapper A., Herlitschke M., Petracic O., Appavou M.S., Müller-Buschbaum P., Frielinghaus H., Richter D. Nanocomposites composed of HEUR polymer and magnetite iron oxide nanoparticles: Structure and magnetic response of the hydrogel and dried state. Polymer, 2015, 60, P. 176-185.

[10] Móczó J., Pukánszky B. Polymer micro and nanocomposites: Structure, interaction, properties. J Ind Eng Chem, 2008,14 , P. 535-563.

[11] Liu D., Pourrahimi A.M., Olsson R.T., Hedenqvist M.S., Gedde U.W. Influence of nanoparticle surface treatment on particle dispersion and interfacial adhesion in low-density polyethylene/aluminium oxide nanocomposites. Eur Polym J, 2015, 66, P. 67-77.

[12] Chou F.-Y., Shih C.-M., Tsai M.-C., Chiu W.-Y., Lue S.J. Functional acrylic acid as stabilizer for synthesis of smart hydrogel particles containing a magnetic $\mathrm{Fe}_{3} \mathrm{O}_{4}$ core. Polymer, 2012, 53, P. 2839-2846.

[13] Gelbrich T., Marten G.U., Schmidt A.M. Reversible thermoflocculation of magnetic core-shell particles induced by remote magnetic heating. Polymer, 2010, 51, P. 2818-2824.

[14] Chen J., Du K., Chen X., Li Y., Huang J., Wu Y., Yang C., Xia X. Influence of surface microstructure on bonding strength of modified polypropylene/aluminum alloy direct adhesion. Appl Surf Sci, 2019, 489, P. 392-402.

[15] Barroso-Bujans F., Serna R., et al. Grafting of poly(acrylic acid) onto an aluminum surface. Langmuir, 2009, 25(16), P. 9094-9100.

[16] Beketov I.V., Safronov A.P., Bagazeev A.V., Larrañaga A., Kurlyandskaya G.V., Medvedev A.I. In situ modification of Fe and Ni magnetic nanopowders produced by the electrical explosion of wire. Journal of Alloys and Compounds, 2014, 586, P. S483-S488.

[17] Safronov A.P., Kurlyandskaya G.V., Chlenova A.A., Kuznetsov M.V., Bazhin D.N., Beketov I.V., Sanchez-Ilarduya M.B., Martinez-Amesti A. Carbon deposition from aromatic solvents onto active intact 3d metal surface at ambient conditions. Langmuir, 2014, 30, P. $3243-3253$.

[18] Kotov Yu.A. Electric explosion of wires as a method for preparation of nanopowders. Journal of Nanoparticle Research, 2003, 5, P. 539-550.

[19] Kurlyandskaya G.V., Bhagat S.M., Safronov A.P., Beketov I.V., Larranaga A. Spherical magnetic nanoparticles fabricated by electric explosion of wire. AIP Advances, 2011, 1, P. 042122.

[20] Petrov A.V., Safronov A.P., Terziyan T.V., Beketov I.V. Effect of the nature of a polymer matrix on the enthalpy of adhesion interactions in composites filled with nickel nanoparticles. Polym Sci Ser A, 2012, 54(11), P. 840-848.

[21] Terziyan T.V., Safronov A.P., Petrov A.V., Panteleeva M.V., Beketov I.V. Thermodynamics of interfacial interactions in composites based on nanodispersed $\mathrm{NiO}$ and methacrylic acid derivatives, Polym Sci Ser A, 2014, 56(1), P. 63-71.

[22] Terziyan T.V., Safronov A.P., Zalyaeva E.R., Beketov I.V., Lakiza N.V. Thermochemical analysis of the interaction between interfaces in composites containing nanodispersed powders of $\mathrm{Al}$ and $\mathrm{Al}_{2} \mathrm{O}_{3}$. Russian Journal of Physical Chemistry A, 2020, 94(12), P. 2508-2513.

[23] Safronov A.P., Bagazeev A.V., Demina T.M., Petrov A.V., Beketov I.V. Active surface modification for iron nanopowders produced by wire electrical explosion. Nanotechnologies in Russia, 2012, 7, P. 5-6.

[24] Hiemenz P.C., Rajagopalan R., Principles of Colloid and Surface Chemistry. Marcel Dekker, New York, 1997,651 p.

[25] Takahashi A., Kawaguchi M. The structure of macromolecules adsorbed on interfaces. Adv Polym Sci, 1982, 46, P. 1-65. 